\title{
Control strategy on two-/four-electron pathway of water splitting by multi-doped carbon based catalysts
}

Xiuqin Wu, ${ }^{\text {\&a }}$ Cheng Zhu, ${ }^{\text {\$a }}$ Liping Wang, ${ }^{a}$ Sijie Guo, ${ }^{a}$ Yalin Zhang, ${ }^{a}$ Hao Li, ${ }^{a}$ Hui Huang, ${ }^{* a}$

Yang Liu, ${ }^{* a}$ Junwang Tang, ${ }^{* b}$ and Zhenhui Kang $* a$

a.Jiangsu Key Laboratory for Carbon Based Functional Materials \& Devices, Institute of Functional Nano \& Soft Materials (FUNSOM), Soochow University, 199 Ren'ai Road, Suzhou, 215123, Jiangsu, PR China E-mail: hhuang0618@ suda.edu.cn (H. Huang); yangl@ suda.edu.cn (Y. Liu); zhkang@suda.edu.cn (Z.H. Kang).

${ }^{\mathrm{b}}$.Department of Chemical Engineering, University College London, London, United Kingdom. Email: junwang.tang@ucl.ac.uk (J.W. Tang).

${ }^{\S}$ These authors contributed equally to this work.

\begin{abstract}
Overall photocatalytic water splitting can proceed through a four-electron or two-electron/twostep pathway. However, it is challenging to manipulate the two- or four-electron pathway. Here, we present that a nitrogen, sulfur, transition metal-codoped carbon based nanostructure, which exhibits reliable photocatalytic ability and satisfactory photostability in water splitting without a need of sacrificial agents. Note that in present system, the transition metal doped structure $(\mathrm{M}=$
\end{abstract}


$\mathrm{Cr}, \mathrm{Cd}, \mathrm{Fe}, \mathrm{Zn}$ ) as a photocatalyst splits water into $\mathrm{H}_{2}$ and $\mathrm{O}_{2}$ through a two-electron pathway while rare earth $(\mathrm{Re})$ elements $(\mathrm{M}=\mathrm{Re}=\mathrm{Sm}, \mathrm{Ce}, \mathrm{Eu}, \mathrm{Pr}, \mathrm{Er})$ doped one as photocatalysts via a four-electron pathway and carbon dots herein work as an electron acceptor and a reduction cocatalyst.

KEYWORDS: carbon based catalysts, photocatalyst, overall photocatalytic water splitting, twoelectron pathway, four-electron pathway

\section{INTRODUCTION}

Harvesting solar energy for the production of hydrogen from water is an ultimate clean and renewable energy strategy for the global environmental issues and the energy crisis. ${ }^{1-4}$ The design and fabrication of high-efficiency, stable and low-cost photocatalysts are key issues for the water splitting. In general, water splitting is an endothermic process, which demands the energy that equal or greater than enthalpy change $(\Delta \mathrm{H})$ required for the decomposition of water into hydrogen and oxygen..$^{5-7}$ Overall water splitting, which directly decompose water into $\mathrm{H}_{2}$ and $\mathrm{O}_{2}$, is an ultimate method for production of $\mathrm{H}_{2}$. However, even intense efforts have been devoted to the design and fabrication of photocatalysis for overall water splitting, big challenges are still remained: (i) few complete photocatalytic water splitting systems are explored compared to photocatalysts for hydrogen production with sacrificial agents and cocatalysts; (ii) few currently reported photocatalysts show considerable stability; (iii) a large overpotential for 
overall four-electron water oxidation to $\mathrm{O}_{2}$ needs to be overcome; and (iv) $\mathrm{H}_{2} \mathrm{O}_{2}$ (produce by competing two-electron reaction) often poisons the photocatalysts..$^{3,8-12}$

The photocatalytic overall water splitting can proceed through four-electron pathway $\left(\mathrm{H}_{2} \mathrm{O} \rightarrow \mathrm{H}_{2}+\mathrm{O}_{2}\right)$ and two-electron two-step pathway $\left(\mathrm{H}_{2} \mathrm{O} \rightarrow \mathrm{H}_{2}+\mathrm{H}_{2} \mathrm{O}_{2} ; \mathrm{H}_{2} \mathrm{O}_{2} \rightarrow \mathrm{H}_{2} \mathrm{O}+\mathrm{O}_{2}\right){ }^{3}$ The four-electron process for oxygen evolution (1.23 eV vs. SHE) is a more workable strategy than the two-electron process for $\mathrm{H}_{2} \mathrm{O}_{2}$ formation (1.78 eV vs. SHE) from the point of view of thermodynamics. The second step of the two-electron two-step pathway $\left(\mathrm{H}_{2} \mathrm{O}_{2} \rightarrow \mathrm{H}_{2} \mathrm{O}+\mathrm{O}_{2}\right)$ is however exothermic $(\Delta \mathrm{G}=-106.1 \mathrm{~kJ} / \mathrm{mol}),{ }^{13,14}$ and if $\mathrm{H}_{2} \mathrm{O}_{2}$ has no significant negative influence on the activity of catalysts and the generated $\mathrm{H}_{2} \mathrm{O}_{2}$ could be disintegrated quickly by the catalysts, the two-electron two-step pathway may also provide a viable and effective approach toward overall water splitting into $\mathrm{H}_{2}$ and $\mathrm{O}_{2}$. Nevertheless, it is difficult to control the fourelectron or two-electron pathway in the process of $\mathrm{H}_{2}$ and $\mathrm{O}_{2}$ evolution from water splitting.

Carbon dots (CDs) exhibit superiority of low cost, easy fabrication, earth-abundance, rapid electron transfer, and electron reservoir properties. ${ }^{15-17}$ CDs not only can be regarded as excellent catalysts, ${ }^{18,19}$ but also used as functional components for photocatalysts and electrocatalysts. ${ }^{20-25}$ At the same time, the multicomponent nanostructure may further improve the catalytic performance. ${ }^{26-30}$ It is reported that the codoping of sulphur $(\mathrm{S})$ and nitrogen $(\mathrm{N})$ with additional electrons can enhance the photo-response property, generate higher electroconductivity, and facilitate transport of the photo induced charge carriers to the surfaces of the catalysts, hence reduce the recombination of the electron-hole pairs. ${ }^{31-35}$ On the other hand, phthalocyanine (Pc)- 
like compounds are an intensely aromatic macrocyclic structure, which have long been examined as catalysts for redox reactions. ${ }^{36,37}$ Motivated by the photoelectric and catalytic activities of Pc, we further expect to combine Pc species with CDs as a way to design and construct carbon based photocatalysts for overall water splitting.

Herein, we present nitrogen, sulfur, transition metal elements-codoped carbon nanostructures prepared by a pyrolysis method. The products are carbon nanostructure based on CDs and Pc structures, namely, what we call "multi- doped carbon based nanostructure" [(SMPc) $\left.)_{\mathrm{n}} / \mathrm{CDs}\right]$. Note that, here, transition metal coordination structure is denoted as $\left[(\mathrm{SMPc})_{\mathrm{n}} / \mathrm{CDs}, \mathrm{M}=\mathrm{Cr}, \mathrm{Cd}\right.$, $\mathrm{Fe}, \mathrm{Zn}]$ and nitrogen, sulfur, rare earth $(\mathrm{Re})$ elements-codoped carbon based nanostructure [rare earth oxide compounds structure as $\left.\left[(\mathrm{SMPc})_{n} / \mathrm{CDs}, \mathrm{M}=\mathrm{Re}=\mathrm{Sm}, \mathrm{Ce}, \mathrm{Eu}, \mathrm{Pr}, \mathrm{Er}\right]\right]$. As photocatalysts, they exhibit efficient photocatalytic ability and good photostability for overall water splitting without sacrificial agents. In present system, the $(\mathrm{SMPc})_{\mathrm{n}} / \mathrm{CDs}(\mathrm{M}=\mathrm{Cr}, \mathrm{Cd}, \mathrm{Fe}$, $\mathrm{Zn)}$ composite splits water into $\mathrm{H}_{2}$ and $\mathrm{O}_{2}$ through a two-electron pathway, while overall photocatalytic water splitting over $(\mathrm{SMPc})_{\mathrm{n}} / \mathrm{CDs}(\mathrm{M}=\mathrm{Re}=\mathrm{Sm}, \mathrm{Ce}, \mathrm{Eu}, \mathrm{Pr}, \mathrm{Er})$ photocatalysts is a four-electron pathway. Moreover, CDs herein work as an electron acceptor and a reduction cocatalyst.

\section{EXPERIMENTAL SECTION}

\section{Materials}


Urea, samarium chloride hexahydrate $\left(\mathrm{SmCl}_{3} \cdot 6 \mathrm{H}_{2} \mathrm{O}\right)$, cerium chloride heptahydrate $\left(\mathrm{CeCl}_{3} \cdot 7 \mathrm{H}_{2} \mathrm{O}\right)$, erbium chloride hexahydrate $\left(\mathrm{ErCl}_{3} \cdot 6 \mathrm{H}_{2} \mathrm{O}\right)$, praseodymium chloride hexahydrate $\left(\mathrm{PrCl}_{3} \cdot 6 \mathrm{H}_{2} \mathrm{O}\right)$, europium chloride hexahydrate $\left(\mathrm{EuCl}_{3} \cdot 6 \mathrm{H}_{2} \mathrm{O}\right)$, chromic chloride hexahydrate $\left(\mathrm{CrCl}_{3} \cdot 6 \mathrm{H}_{2} \mathrm{O}\right)$, cadmium chloride hydrate $\left(\mathrm{CdCl}_{2} \cdot 2.5 \mathrm{H}_{2} \mathrm{O}\right)$, ferric chloride hexahydrate $\left(\mathrm{FeCl}_{3} \cdot 6 \mathrm{H}_{2} \mathrm{O}\right)$, zinc chloride $\left(\mathrm{ZnCl}_{2}\right)$, ammonium molybdate tetrahydrate [( $\left.\left.\mathrm{NH}_{4}\right)_{2} \mathrm{MoO}_{4} \cdot 4 \mathrm{H}_{2} \mathrm{O}\right]$, pyromellitic dianhydride (PMDA), 4-sulphophthalic anhydride, silver nitrate $\left(\mathrm{AgNO}_{3}\right)$, lead nitrate $\left[\mathrm{Pb}\left(\mathrm{NO}_{3}\right)_{2}\right]$, 1-butyl-3-methylimidazolium hexafluorophosphate (BMIMPF6), and ferrocene are of analytic purity and used without further purification.

\section{Synthesis of CDs and (SMPc) $/$ /CDs}

CDs were synthesized by an electrochemical etching method with graphite rods as carbon source reported by our group previously. ${ }^{38}$ The obtained brown CDs solution with a uniform size in range of 5-10 $\mathrm{nm}$ is frozen drying to get the fluffy CDs powder. After that, $50 \mathrm{mg}$ CDs powder was added in $100 \mathrm{~mL}$ ultrapure water to form a solution of $0.5 \mathrm{~g} / \mathrm{L}$. (SMPc) $/ \mathrm{CDs}$ was fabricated by a modified method reported by Frank and co-workers previously. ${ }^{39}$ Briefly, $18 \mathrm{mmol}$ (1.13 g) urea, $1.9 \mathrm{mmol}$ metal chloride, $0.28 \mathrm{mmol}(0.063 \mathrm{~g}) \mathrm{PMDA}$, and $0.02 \mathrm{~g}\left(\mathrm{NH}_{4}\right)_{2} \mathrm{MoO}_{4} \cdot 4 \mathrm{H}_{2} \mathrm{O}$ were added to a crucible and mixed well. Then the mixture was heated to molten state by an alcohol burner. Afterwards, $0.5 \mathrm{~g}$ 4-sulfophthalic anhydride was quickly put into the crucible under vigorous stirring until the mixture appeared dramatic expansion. Subsequently, $4 \mathrm{~mL}$ CDs were injected dropwise into the crucible. At last, the mixture was maintained at $250{ }^{\circ} \mathrm{C}$ for 90 min in 
muffle furnace. Finally, a fluffy solid was obtained, and it was thoroughly washed with diluted hydrochloric acid and distilled water several times to remove solid oxides that may form and other impurities. Then, the obtained samples were dried in a vacuum oven at $60{ }^{\circ} \mathrm{C}$ for $12 \mathrm{~h}$. The $(\mathrm{SMPc})_{\mathrm{n}}$ was synthesized under the same conditions without CDs. Under the real condition of the reaction, the prepared $(\mathrm{SMPc})_{\mathrm{n}}(\mathrm{M}=\mathrm{Cr}, \mathrm{Cd}, \mathrm{Fe}, \mathrm{Zn})$ was a transition metal coordination structure, ${ }^{40}$ and the $(\mathrm{SMPc})_{\mathrm{n}}(\mathrm{M}=\mathrm{Sm}, \mathrm{Ce}, \mathrm{Eu}, \mathrm{Pr}, \mathrm{Er})$ was a complex of metal-free phthalocyanine and rare earth oxide..$^{41,42}$

\section{Photocatalytic activity test}

The photocatalytic reactions were conducted in a Pyrex glass photoreactor with a flat window at the top for illumination connected to a closed gas-circulation system. $80 \mathrm{mg}$ catalyst powder was dispersed in $100 \mathrm{~mL}$ ultrapure water, and then the system was completely degassed to remove air through a vacuuming procedure. Under ambient conditions and constant stirring, the suspension was irradiated by AM 1.5G solar simulator (MICROSOLAR 300, Beijing Perfectlight Co. Ltd, China). For evolved gas detection, an online GC-7900 gas chromatograph set up with a thermal conductivity detector (TCD) and $5 \AA$ molecular sieve columns was employed. The oven, injection port and detector temperatures of gas chromatograph were held at 80,100 , and $120{ }^{\circ} \mathrm{C}$, respectively. Argon (Ar) was used as carrier gas with the flow rate of $30 \mathrm{~mL} / \mathrm{min}$. To check the reproducibility and stability of catalysts, the suspension after reaction was centrifuged and reused for repeated tests. 


\section{Determination of reduction sites and oxidation sites}

It has been reported that $\mathrm{Ag}$ particles are reductively photodeposited on reduction sites and $\mathrm{PbO}_{2}$ particles are oxidatively photodeposited on oxidation sites as follows: ${ }^{43,44}$

$$
\begin{gathered}
\mathrm{Ag}^{+}+\mathrm{e}^{-} \rightarrow \mathrm{Ag} \\
\mathrm{Pb}^{2+}+2 \mathrm{H}_{2} \mathrm{O}+2 \mathrm{~h}^{+} \rightarrow \mathrm{PbO}_{2}+4 \mathrm{H}^{+}
\end{gathered}
$$

Therefore, in our work, $2 \mathrm{mg}$ catalyst powder was dispersed in $30 \mathrm{~mL}$ of ultrapure water, then the suspension was irradiated by a $300 \mathrm{~W}$ Xe-lamp for $3 \mathrm{~h}$ under continuous stirring. Subsequently, about $0.5 \mathrm{mg} \mathrm{AgNO}_{3}$ [or $\mathrm{Pb}\left(\mathrm{NO}_{3}\right)_{2}$ ] powder was added to the above suspension and the mixture was continuously stirred for $30 \mathrm{~min}$ in darkness. The obtained intermixture was centrifuged and further analysed by high-resolution transmission electron microscopy (HRTEM) measurements to determine the reduction sites (or oxidation sites).

\section{Characterizations}

Scanning electron microscopy (SEM) and energy dispersive X-ray spectroscopy (EDS) measurements were carried out using a FEI-quanta 200 scanning electron microscope with an accelerating voltage of $20 \mathrm{kV}$. Transmission electron microscopy (TEM) and High-resolution TEM (HRTEM) images were taken on a FEI-Tecnai F20 transmission electron microscope with an accelerating voltage of $200 \mathrm{kV}$. The TEM samples were prepared through dropping the solution onto a copper grid with polyvinyl supporting film and dried in air. The X-ray diffraction spectra (XRD) measurements were performed on an X-ray diffractometer (Empyrean, Holland 
Panalytical) with nickel-filtered $\mathrm{Cu} \mathrm{K \alpha}(\lambda=0.154178 \mathrm{~nm})$ radiation as the X-ray source. Fourier transform infrared spectra (FTIR) were obtained with a Nicolet 6700 spectrometer using a standard $\mathrm{KBr}$ pellet technique in the scan range of $400-4000 \mathrm{~cm}^{-1}$. X-ray photoelectron spectra (XPS) were carried out using a KRATOS Axis ultra-DLD X-ray photoelectron spectrometer with a monochromatised $\mathrm{Mg} \mathrm{K} \alpha$ X-ray source $(h v=1283.3 \mathrm{eV})$. The UV-vis spectra were obtained via a Lambda 750 (Perkin Elmer) spectrophotometer in the wavelength range of 200-800 nm.

\section{Electrochemical Characterization}

The cyclic voltammetry (CV), linear sweep voltammograms (LSV), current-time (i-t) curves and electron transfer number (n) experiments were carried out in a standard threeelectrode cell with a computer-controlled CHI 920C workstation (CH Instruments, Chenhua, Shanghai, China) at room temperature. A platinum $(\mathrm{Pt})$ wire and an $\mathrm{Ag} / \mathrm{AgCl}(3 \mathrm{M} \mathrm{KCl})$ electrode or a saturated calomel electrode (SCE) were used as the counter electrode and the reference electrode, respectively. The glassy carbon (GC) electrode (3 $\mathrm{mm}$ diameter) was polished to a mirror finish, thoroughly cleaned and dried before use. $10 \mu \mathrm{L}$ catalyst solution $(1.5$ $\mathrm{mg} \cdot \mathrm{mL}^{-1}$ ) and $5 \mu \mathrm{L} 0.5 \mathrm{wt} \%$ Nafion solution were dropped onto the surface of a treated GC electrode and left to dry naturally to prepare the working electrode. Before electrochemical testing, the working electrode was immersed into the electrolyte and activated for 30 min to keep it stable. The CV curves were performed in $\mathrm{N}_{2}$-saturated 0.1 M BMIMPF6 solution with a scan rate of $50 \mathrm{mV} / \mathrm{s}$. The i-t curves were gained at open circuit potential in ultrapure water. The 
electron transfer number was studied by rotating disk-ring electrodes (RRDE). The RRDE collection experiments for $(\mathrm{SMPc})_{\mathrm{n}} / \mathrm{CDs}$ were performed in $\mathrm{N}_{2}$ saturated ultrapure water at 100 $\mathrm{mV} / \mathrm{s}$ with a rotation speed of $1600 \mathrm{rpm}$. The disk potential was set at open circuit potential. The ring potential was set at $0.9 \mathrm{~V}$ vs. SCE. A Xe lamp $(300 \mathrm{~W})$ positioned $2 \mathrm{~cm}$ away from the working electrode was used as the light source.

\section{Results and discussion}



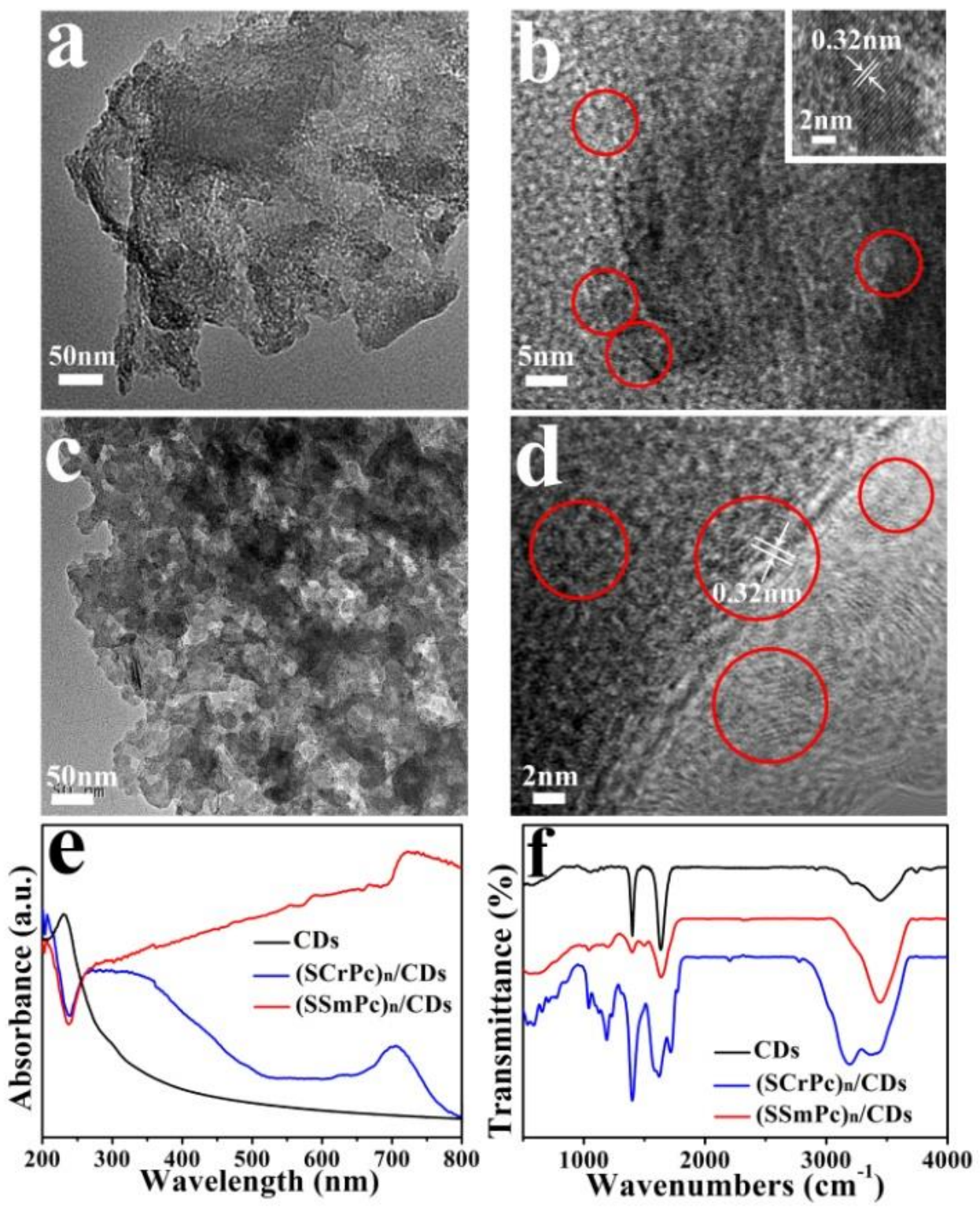

Figure 1. Typical TEM (a) and HRTEM (b) images of $(\mathrm{SCrPc})_{n} / \mathrm{CDs}$, the scale bar inserted in (b) is $2 \mathrm{~nm}$. Typical TEM (c) and HRTEM (d) images of (SSmPc) $)_{n} / C D s$. UV-vis absorption spectra (e) and FTIR spectra (f) of (SSmPc) $)_{n} / \mathrm{CDs}$ (red trace), $(\mathrm{SCrPc})_{\mathrm{n}} / \mathrm{CDs}$ (blue trace) and CDs (black trace), respectively. The red circles in Figure b and d represent CDs. 
In our experiments, briefly, a modified method of solid-state synthesis of Pc was used and CDs as a reaction agent were introduced. ${ }^{39,45}$ Then the obtained products are the so called "multidoped carbon nanostructure" $\left[(\mathrm{SMPc})_{\mathrm{n}} / \mathrm{CDs}\right]$. Figure 1a shows TEM images of $(\mathrm{SCrPc})_{\mathrm{n}} / \mathrm{CDs}$, indicating the obtained nanostructure is irregular. Figure S2 displays the TEM and HRTEM images of the as-prepared CDs, from which we can see that these CDs possess uniform size in the range of 5-10 $\mathrm{nm}$ and the clear lattice spacing of $0.32 \mathrm{~nm}$ is in good agreement with the (002) crystallographic plane of graphite. ${ }^{38}$ Figure $2 \mathrm{~b}$ exhibits the HRTEM image of $(\mathrm{SCrPc})_{\mathrm{n}} / \mathrm{CDs}$. As shown, the CDs are consistently deposited on the carbon nanostructure and as stable cocatalysts, in which the lattice fringes of (002) plane of graphitic carbon with an interplanar spacing of 0.32 nm could be easily identified. ${ }^{46}$ Figure S3 describes the SEM image, as well as the corresponding EDS elemental mapping images of $(\mathrm{SCrPc})_{n} / \mathrm{CDs}$, which declare that the $\mathrm{C}, \mathrm{N}, \mathrm{O}, \mathrm{S}$, and $\mathrm{Cr}$ were uniformly distributed in the carbon nanostructure and C, N, O, S and $\mathrm{Cr}$ were successfully doped in the nanostructure. From the TEM image of $(\mathrm{SSmPc})_{\mathrm{n}} / \mathrm{CDs}$ (Figure 1c), it can be observed that the $(\mathrm{SSmPc})_{\mathrm{n}} / \mathrm{CDs}$ were also morphologically irregular and CDs were spotted on the surface of the carbon nanostructure. To visualize the spatial distribution of elements, the EDX technique was used to analyze the $(\mathrm{SSmPc})_{\mathrm{n}} / \mathrm{CDs}$, and the results are shown in Figure $\mathrm{S} 4$. It can be seen that the elements of $\mathrm{C}, \mathrm{N}, \mathrm{O}, \mathrm{S}$ and Sm spread evenly on the whole carbon nanostructure. The HRTEM image of $(\mathrm{SSmPc})_{\mathrm{n}} / \mathrm{CDs}$ is shown in Figure 1d with an interplanar spacing of $0.32 \mathrm{~nm}$, assigning to the (002) plane of graphitic carbon. These results confirmed that the CDs were successfully loaded onto the obtained carbon nanostructures. 
The optical properties of the as-prepared samples were investigated by UV-vis absorption spectra (Figure 1e). It can be clearly observed that both $(\mathrm{SCrPc})_{\mathrm{n}} / \mathrm{CDs}$ (blue trace) and $(\mathrm{SSmPc})_{\mathrm{n}} / \mathrm{CDs}$ (red trace) possess stronger and wider visible light absorption bands compared with CDs (black trace), which only have absorption peak from $230-280 \mathrm{~nm}$ ascribed to various $\pi-\pi^{*}$ and $\mathrm{n}-\pi^{*}$ transitions. ${ }^{47}$ Moreover, the enhanced light absorption is helpful for improving the capacity of photocatalytic overall water splitting. Fourier transform infrared (FTIR) spectra were employed to characterize the surface functional groups of $(\mathrm{SMPc})_{\mathrm{n}} / \mathrm{CDs}$. As shown in Figure 1f, the FTIR spectrum of CDs (black trace) demonstrates CDs prepared in our work possess ample functional groups. The peak around $1630 \mathrm{~cm}^{-1}$ corresponds to the stretching vibrations of $\mathrm{C}=\mathrm{C} / \mathrm{C}=\mathrm{O}$ bonds. ${ }^{48,49}$ The absorption bands at $3400 \mathrm{~cm}^{-1}$ and $1050 \mathrm{~cm}^{-1}$ are assigned to $\mathrm{C}-\mathrm{OH}$ and $\mathrm{C}-\mathrm{O}-\mathrm{C}$, respectively, which confirms the existence of carboxyl groups $(-\mathrm{COOH}) .{ }^{49}$ For $(\mathrm{SCrPc})_{n} / \mathrm{CDs}$ (blue trace) and $(\mathrm{SCrPc})_{n} / \mathrm{CDs}$ (red trace), both the characteristic peaks of $\mathrm{CDs}$ were also observed, indicating the existence of CDs in the complex photocatalysts. The bands in the region of $1640-1630 \mathrm{~cm}^{-1}$ arise from the stretching vibrations of $\mathrm{C}=\mathrm{N}$ bonds, ${ }^{48}$ while the weak peaks at $1200-1600 \mathrm{~cm}^{-1}$ region correspond to the characteristic absorption of the typical aromatic $\mathrm{CN}$ heterocycles. ${ }^{50}$ The crystalline structure of the as-prepared samples have been further confirmed by XRD (Figure S5 and S6). The XRD pattern of CDs shows a prominent peak at $26^{\circ}$ referring to the amorphous carbon ${ }^{38,51}$. In the XRD patterns of (SMPc) $/$ /CDs, the broad peaks at about $27^{\circ}$ correspond to amorphous carbon, and no extra characteristic peaks were detected. These results indicate that the as-prepared (SMPc) $)_{n} / C D s$ are amorphous carbon structure. 

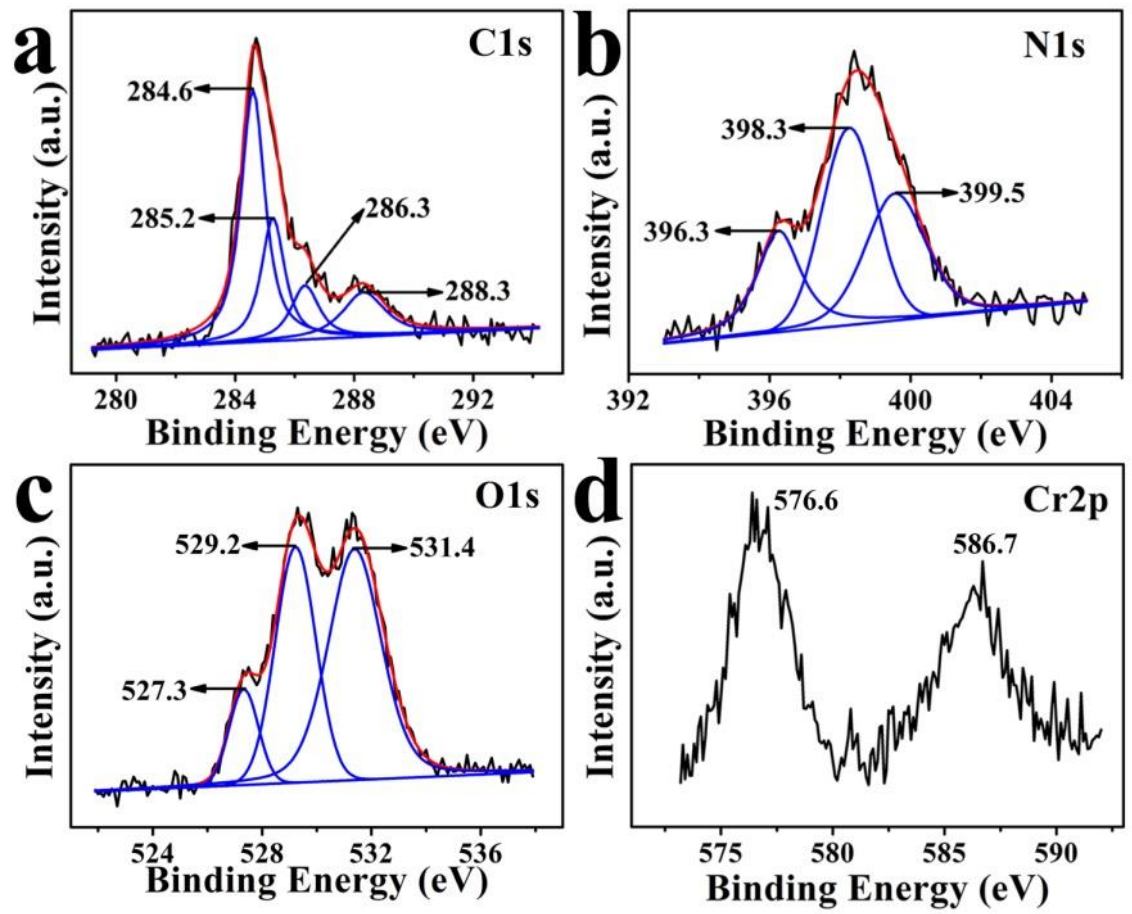

Figure 2. The high resolution $\mathrm{C}$ 1s (a), $\mathrm{N}$ 1s (b), O 1s (c) and Cr 2p (d) XPS spectra of $(\mathrm{SCrPc})_{\mathrm{n}} / \mathrm{CDs}$.

The X-ray photoelectron spectroscopy (XPS) was performed to further explore the surface compositions and chemical states of $(\mathrm{SMPc})_{\mathrm{n}} / \mathrm{CDs}$, and the corresponding results are shown in Figure 2, Figure 3 and Figure S7. Figure S7a shows the fully scanned spectrum of $(\mathrm{SCrPc})_{\mathrm{n}} / \mathrm{CDs}$, which confirms the existence of $\mathrm{C}, \mathrm{N}, \mathrm{O}, \mathrm{S}$ and $\mathrm{Cr}$ elements (the signal of $\mathrm{In}$ is due to the substrate). The high resolution $\mathrm{C}$ 1s XPS spectra of $(\mathrm{SCrPc})_{n} / \mathrm{CDs}$ (Figure 2a) could be divided into four deconvoluted peaks with binding energies of 284.6, 285.2, 286.3 and $288.3 \mathrm{eV}$, which correspond to $\mathrm{C}-\mathrm{C} / \mathrm{C}=\mathrm{C},(\mathrm{C}) 3-\mathrm{N} / \mathrm{C}-\mathrm{OH}$ and $\mathrm{N}-\mathrm{C}=\mathrm{N} / \mathrm{C}=\mathrm{O}$, respectively. ${ }^{3,52}$ The $\mathrm{N}$ 1s core level spectrum of $(\mathrm{SCrPc})_{\mathrm{n}} / \mathrm{CDs}$ (Figure $2 \mathrm{~b}$ ) can be fitted into three peaks, which can be ascribed to $\mathrm{N}-\mathrm{Cr}(396.3 \mathrm{eV}), \mathrm{C}=\mathrm{N}-\mathrm{C}(398.3 \mathrm{eV})$, and $\mathrm{N}-(\mathrm{C}) 3(399.5 \mathrm{eV})$, respectively. ${ }^{3,53}$ The presence of 
$\mathrm{N}-\mathrm{Cr}$ may demonstrate the formation of transition metal coordination structure (metal phthalocyanine). The O1s core level spectrum presented in Figure $2 \mathrm{c}$ is fitted with three different signals with binding energies of 527.3, 529.2, and $531.4 \mathrm{eV}$, which are attributed to O-H, O-Cr and adsorbed water, respectively. ${ }^{49}$ The high resolution $\mathrm{Cr} 2 \mathrm{p}$ spectrum of $(\mathrm{SCrPc})_{\mathrm{n}} / \mathrm{CDs}$ shown in Figure 2e suggested $\mathrm{Cr} 2 \mathrm{p} 1 / 2$ and $\mathrm{Cr} 2 \mathrm{p} 3 / 2$ peaks located at 586.7 and $576.6 \mathrm{eV}$, respectively, which can be assigned to chromic oxide. ${ }^{54,55}$ In Figure S7b, the full XPS survey spectrum of $(\mathrm{SSmPc})_{\mathrm{n}} / \mathrm{CDs}$ shows the $\mathrm{C} 1 \mathrm{~s}, \mathrm{~N} 1 \mathrm{~s}, \mathrm{O} 1 \mathrm{~s}, \mathrm{~S} 2 \mathrm{p}$ and $\mathrm{Sm} 3 \mathrm{~d}$ peaks. The high resolution $\mathrm{C}$ 1s XPS spectrum of $(\mathrm{SSmPc})_{\mathrm{n}} / \mathrm{CDs}$ is shown in Figure 3a, which represent four main peaks located at about $284.6,285.5,286.4$ and $288.8 \mathrm{eV}$, corresponding to $\mathrm{C}-\mathrm{C} \mathrm{sp}^{2}$ and $\mathrm{sp}^{3}$ hybridized components, $\mathrm{C}-\mathrm{N} / \mathrm{C}-\mathrm{OH}$ and $\mathrm{N}-\mathrm{C}=\mathrm{N} / \mathrm{C}=\mathrm{O}$, respectively. ${ }^{56,57}$ Deconvolution of the high-resolution $\mathrm{N}$ 1s XPS spectra of $(\mathrm{SSmPc})_{\mathrm{n}} / \mathrm{CDs}$ in Figure $3 \mathrm{~b}$ indicates three prominent peaks at $398.7,399.9$ and $401.1 \mathrm{eV}$, attributed to $\mathrm{C}-\mathrm{N}-\mathrm{C}$, pyridine and urotropine-type nitrogen, respectively. ${ }^{50,58}$ The three peaks that can be distinguished in the XPS O 1s spectrum of $(\mathrm{SSmPc})_{\mathrm{n}} / \mathrm{CDs}$ are shown in Figure $3 \mathrm{c}$. The three resolved peaks of $\mathrm{O}$ 1s core level spectrum at about 530.2, 531.8 and $533.7 \mathrm{eV}$ are assigned to lattice oxygen, surface hydroxyl groups, and adsorbed water, respectively. ${ }^{59}$ The high resolution $\mathrm{Sm} 3 \mathrm{~d}$ spectrum of $(\mathrm{SSmPc})_{\mathrm{n}} / \mathrm{CDs}$ (Figure 3d) shows two bands at binding energies of 1084.5 and $1111.5 \mathrm{eV}$, which are attributed to the $3 \mathrm{~d}$ $5 / 2$ and $3 \mathrm{~d} 3 / 2$ ionization of $\mathrm{Sm}^{3+}$, respectively, indicating that $\mathrm{Sm}$ species may be existed in the form of $\mathrm{Sm}_{2} \mathrm{O}_{3}{ }^{60}$ These results demonstrate that the structure of $(\mathrm{SCrPc})_{n} / \mathrm{CDs}$ is different from that of the $(\mathrm{SSmPc})_{\mathrm{n}} / \mathrm{CDs}$ (as illustrated in Figure $\mathrm{S} 8$ ). 

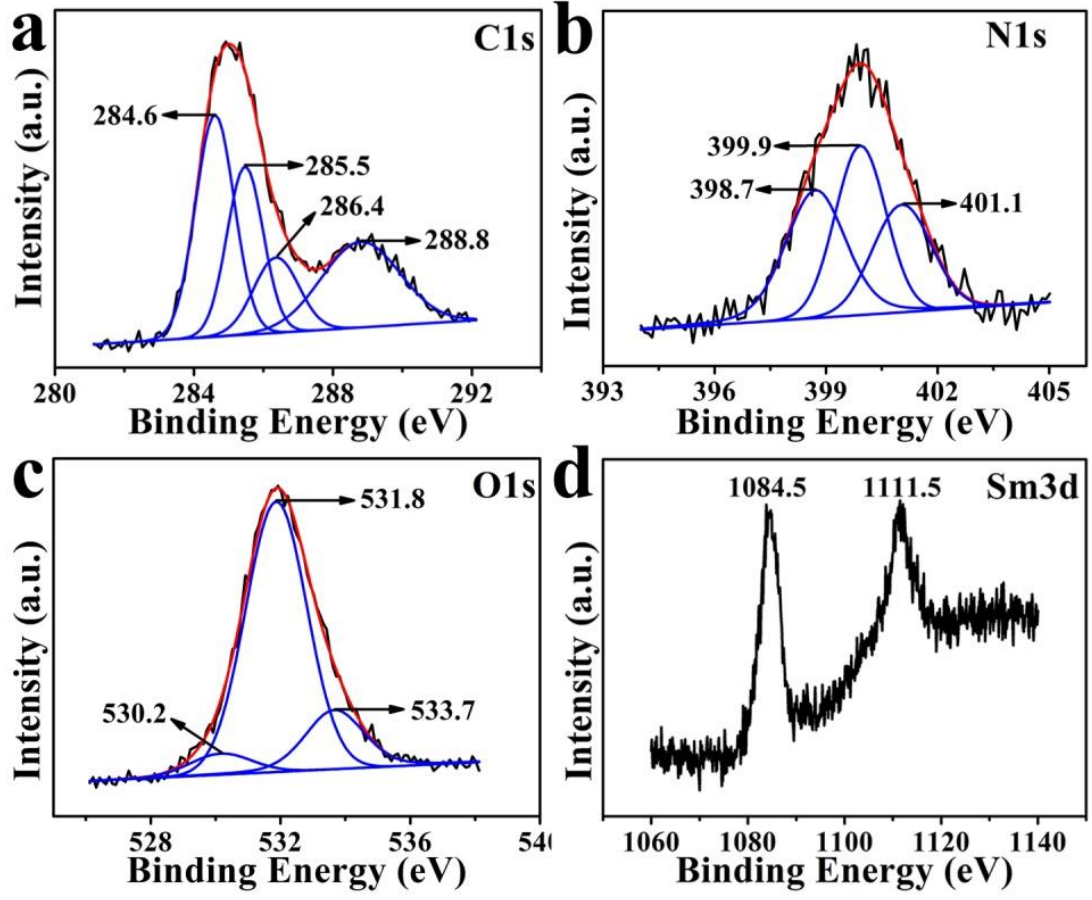

Figure 3. The high resolution $\mathrm{C}$ 1s (a), $\mathrm{N}$ 1s (b), O 1s and (c) Sm 3d, (d) XPS spectra of $(\mathrm{SSmPc})_{\mathrm{n}} / \mathrm{CDs}$.

To evaluate the highest occupied molecular orbital (HOMO) and the lowest unoccupied molecular orbital (LUMO) of $(\mathrm{SMPc})_{\mathrm{n}} / \mathrm{CDs}$, the cyclic voltammetry $(\mathrm{CV})$ experiments were performed. Figure $4 \mathrm{a}$ and $4 \mathrm{c}$ display the cyclic voltammograms $(\mathrm{CV})$ of $(\mathrm{SCrPc})_{\mathrm{n}} / \mathrm{CDs}$ and $(\mathrm{SSmPc})_{\mathrm{n}} / \mathrm{CDs}$ (the ferrocene redox system was introduced as an external standard). The HOMO and LUMO energy levels were calculated from the onset of oxidation $\left(E_{\mathrm{ox}}\right)$ and reduction $\left(E_{\mathrm{red}}\right)$ potentials as determined by $\mathrm{CV}$ and the reference energy level for ferrocene $(4.8 \mathrm{eV}$ below the vacuum level) according to the following equations: ${ }^{61}$

$$
\begin{aligned}
& E_{\mathrm{HOMO}}=-\left(E_{\text {onset }^{\mathrm{ox}}}-E_{\text {ferrocene }}+4.80\right) \mathrm{eV} \\
& E_{\text {LUMO }}=-\left(E_{\text {onset }^{\text {red }}}-E_{\text {ferrocene }}+4.80\right) \mathrm{eV}
\end{aligned}
$$




$$
E_{\mathrm{g}}(\text { band gap })=E_{\text {onset }}^{\text {ox }}-E_{\text {onset }}^{\text {red }}
$$

Where $E_{\text {ferrocene }}$ is the onset of the oxidation potential ( $v s . \mathrm{Ag} / \mathrm{AgCl}$ ) of ferrocene. The calculated HOMO/LUMO energy levels are -6.45/-4.04 eV for $(\mathrm{SCrPc})_{\mathrm{n}} / \mathrm{CDs}$, and -5.88/-3.89 eV for $(\mathrm{SCrPc})_{\mathrm{n}} / \mathrm{CDs}$. The calculated HOMO/LUMO energy levels and $E_{\mathrm{g}}$ values of different metal doped in $(\mathrm{SMPc})_{\mathrm{n}} / \mathrm{CDs}$ photocatalysts are also shown in Table 1. Figure $4 \mathrm{~b}$ shows band structure diagram of $(\mathrm{SCrPc})_{n} / \mathrm{CDs}$, in which the conduction band $(\mathrm{CB})$ and valence band $(\mathrm{VB})$ of the photocatalyst straddled the reduction and oxidation potentials of water with +0 and $+1.78 \mathrm{~V}$ (and +1.23 V) vs. reversible hydrogen electrode (RHE), respectively, thus photocatalytic water splitting into $\mathrm{H}_{2}$ and $\mathrm{O}_{2} / \mathrm{H}_{2} \mathrm{O}_{2}$ using $(\mathrm{SCrPc})_{n} / \mathrm{CDs}$ as a photocatalyst can be achieved in theory. ${ }^{3}$ Figure $4 d$ displays the energy level diagram of the $(\mathrm{SSmPc})_{\mathrm{n}} / \mathrm{CDs}$ photocatalyst as compared to the potentials for water reduction and oxidation. As can be seen, the $\mathrm{CB}$ and VB of $(\mathrm{SSmPc})_{\mathrm{n}} / \mathrm{CDs}$ have suitable potential levels for water reduction and oxidation. Therefore, the overall charge transfers are allowed in the present photocatalytic system. ${ }^{27,62}$ 

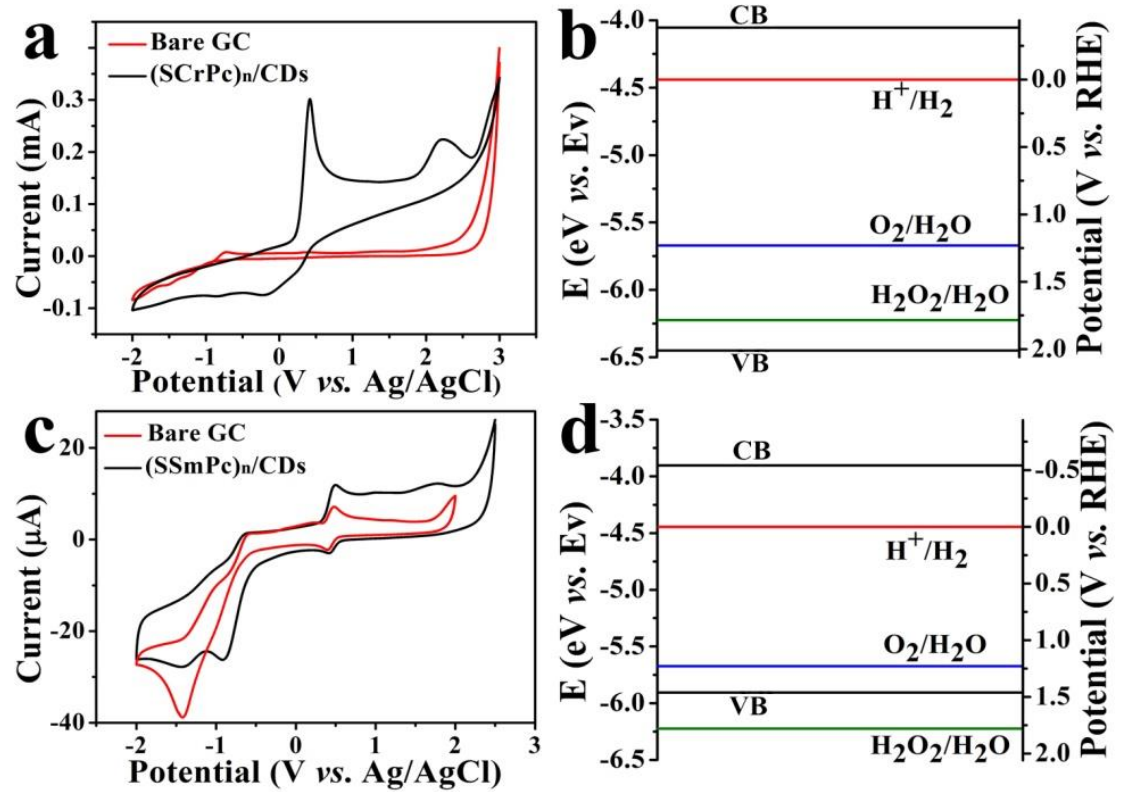

Figure 4. The $\mathrm{CV}$ (a) and band structure diagram (b) of $(\mathrm{SCrPc})_{n} / \mathrm{CDs}$. The $\mathrm{CV}$ (c) and band structure diagram $(\mathrm{d})$ of $(\mathrm{SSmPc})_{\mathrm{n}} / \mathrm{CDs}$.

Figure S9 shows the photoelectrical responses (instantaneous change in current upon illumination) of $(\mathrm{SCrPc})_{\mathrm{n}} / \mathrm{CDs}($ Figure $\mathrm{S} 9 \mathrm{a})$ and $(\mathrm{SSmPc})_{\mathrm{n}} / \mathrm{CDs}$ (Figure $\left.\mathrm{S} 9 \mathrm{~b}\right)$ under intermittent irradiation. Obviously, as shown in Figure $\mathrm{S} 9 \mathrm{a}$, the photocurrent density of the $(\mathrm{SCrPc})_{\mathrm{n}} / \mathrm{CDs}$ rapidly increased to a value of $270.6 \mathrm{nA} / \mathrm{cm}^{2}$ at the time of $30 \mathrm{~s}$ during illumination "On", and then sharply returned to its initial value when the light was turned "Off”. The ' On'” and 'Off'"state currents for each cycle shown here were maintained within the noise level, further demonstrating excellent stability and reproducible characteristics of the photocurrent for $(\mathrm{SCrPc})_{\mathrm{n}} / \mathrm{CDs}$ photocatalyst over this time interval. From Figure $\mathrm{S} 9 \mathrm{~b}$, the $(\mathrm{SSmPc})_{\mathrm{n}} / \mathrm{CDs}$ sample exhibits a residual current photocurrent when light immediately removed. The relatively slower decay of the photocurrent may be due to trapped charge carriers with a prolonged lifetime. These 
results suggested that the $(\mathrm{SMPc})_{\mathrm{n}} / \mathrm{CDs}$ catalysts are of high photoelectric response and good photocurrent stability.
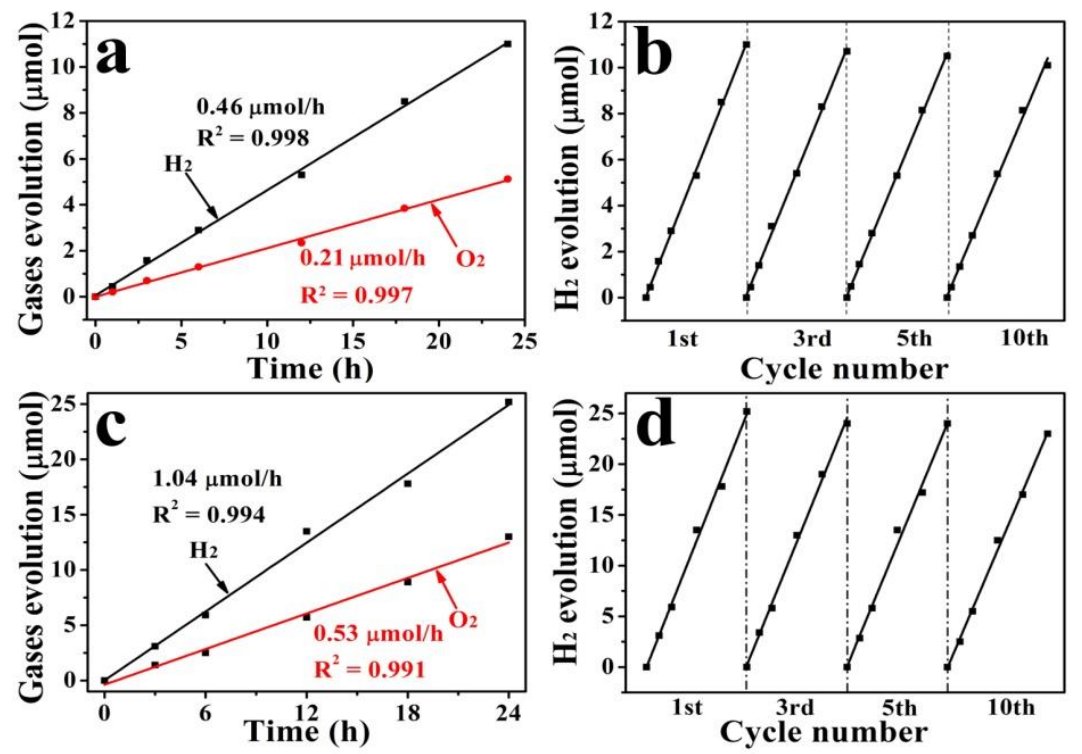

Figure 5. (a) Typical time course of $\mathrm{H}_{2}$ and $\mathrm{O}_{2}$ production, and (b) the stability of photocatalytic water splitting over $(\mathrm{SCrPc})_{n} / \mathrm{CDs}$ photocatalyst. (c) Typical time course of $\mathrm{H}_{2}$ and $\mathrm{O}_{2}$ production, and (d) the stability of photocatalytic water splitting over $(\mathrm{SSmPc})_{\mathrm{n}} / \mathrm{CDs}$ photocatalyst.

In the following experiments, the performance of photocatalytic water splitting under sunlight irradiation using $(\mathrm{SMPc})_{\mathrm{n}} / \mathrm{CDs}$ carbon nanostructures as photocatalysts was investigated without any sacrificial agent or cocatalyst. Figure 5a describes the photocatalytic activity of ( $\mathrm{SCrPc})_{n} / \mathrm{CDs}$ for water splitting. The $\mathrm{H}_{2}$ and $\mathrm{O}_{2}$ in a molar ratio of $\mathrm{H}_{2} / \mathrm{O}_{2}$ is 2.17 were detected by gas chromatograph in the experimental period. The $\mathrm{H}_{2}$ and $\mathrm{O}_{2}$ evolution rates $(0.46 \mu \mathrm{mol} / \mathrm{h}$ and $0.21 \mu \mathrm{mol} / \mathrm{h}$, respectively) remained almost unchanged for $24 \mathrm{~h}$ on course. For the 
$(\mathrm{SSmPc})_{\mathrm{n}} / \mathrm{CDs}$ as photocatalyst (Figure $5 \mathrm{c}$ ), both $\mathrm{H}_{2}$ and $\mathrm{O}_{2}$ are produced simultaneously with a $\mathrm{H}_{2} / \mathrm{O}_{2}$ ratio close to $2.0\left(\mathrm{H}_{2}\right.$ evolution rate of $1.04 \mu \mathrm{mol} / \mathrm{h}$ and $\mathrm{O}_{2}$ evolution rate of $\left.0.53 \mu \mathrm{mol} / \mathrm{h}\right)$. Table 1 presents photocatalytic activities of all the $(\mathrm{SMPc})_{\mathrm{n}} / \mathrm{CDs}$ for water splitting. It can be seen that part of $(\mathrm{SMPc})_{\mathrm{n}} / \mathrm{CDs}(\mathrm{M}=\mathrm{Sm}, \mathrm{Ce})$ have shown higher catalytic activity than that of $(\mathrm{SMPc})_{\mathrm{n}} / \mathrm{CDs}(\mathrm{M}=\mathrm{Cr}, \mathrm{Cd}, \mathrm{Fe}, \mathrm{Zn})$, which may result from the orbital hybridization of $4 \mathrm{f}$ electrons that able to inhibit the combination of photo-excited electrons and holes and enlarge the light adsorption. ${ }^{63}$ Good stability is one of the important factors for the practical applications of photocatalysts in overall water splitting. Figure $5 \mathrm{~b}$ and d confirm stable photocatalytic activities of $(\mathrm{SCrPc})_{\mathrm{n}} / \mathrm{CDs}$ and $(\mathrm{SSmPc})_{\mathrm{n}} / \mathrm{CDs}$ as photocatalysts under optimum reaction conditions. After the first cycle $(24 \mathrm{~h}), \mathrm{H}_{2}$ could still be collected with nine more cycles. The average $\mathrm{H}_{2}$ gas evolution rates for $(\mathrm{SCrPc})_{\mathrm{n}} / \mathrm{CDs}$ and $(\mathrm{SSmPc})_{\mathrm{n}} / \mathrm{CDs}$ are $0.43 \mu \mathrm{mol} / \mathrm{h}$ and $1.01 \mu \mathrm{mol} / \mathrm{h}$, respectively. The slight reduction of the $\mathrm{H}_{2}$ evolution activity may probably attribute to the loss of photocatalysts in the filtration processes.

A series of control experiments were also performed. First, the control experiments were carried out under different conditions: (1) in the presence of (SMPc) $)_{n} / C D s$ but under dark and (2) with full range irradiation (UV + visible light) but in the absence of the $(\mathrm{SMPc})_{\mathrm{n}} / \mathrm{CDs}$. The results demonstrated that no $\mathrm{H}_{2}$ was detected. Then, we further compared the photocatalytic abilities of $(\mathrm{SMPc})_{n} / \mathrm{CDs}$ with different atomic percent. In the preparation process of $(\mathrm{SMPc})_{\mathrm{n}} / \mathrm{CDs}$, we only adjusted the amount of urea and CDs with other conditions unchanged. Table S1 and S2 shows 
the relationship between the rate of $\mathrm{H}_{2}$ evolution and the volume of $\mathrm{CDs}(0,4,8 \mathrm{~mL}$, the concentration of CDs was $0.5 \mathrm{~g} / \mathrm{L})$ over $(\mathrm{SMPc})_{\mathrm{n}} / \mathrm{CDs}$ in the case of the mass of the urea was $0.56 \mathrm{~g}, 1.13 \mathrm{~g}$ and $1.69 \mathrm{~g}$, respectively. It can be found that the $(\mathrm{SCrPc})_{\mathrm{n}} / \mathrm{CDs}$ and $(\mathrm{SSmPc})_{\mathrm{n}} / \mathrm{CDs}$ did not exhibit obvious performance of photocatalytic hydrogen production regardless of the amount of CDs when the mass of urea was $0.56 \mathrm{~g}$ or $1.69 \mathrm{~g}$, which may be due to the fact that the $(\mathrm{SMPc})_{\mathrm{n}}$ structure (Pc structure) did not form in the reaction process. On the other hand, even though the mass of urea was $1.13 \mathrm{~g}$, the obtained $(\mathrm{SMPc})_{\mathrm{n}} / \mathrm{CDs}$ carbon nanostructure as a photocatalyst have barely photocatalytic water splitting properties when the amount of CDs was $0 \mathrm{~mL}$. With the increase of the volume of CDs $(8 \mathrm{~mL}$, the urea was $1.13 \mathrm{~g})$, the photocatalytic activity of $(\mathrm{SMPc})_{\mathrm{n}} / \mathrm{CDs}$ gradually decreased $\left[0.27 \mu \mathrm{mol} / \mathrm{h}\right.$ for $(\mathrm{SMPc})_{\mathrm{n}} / \mathrm{CDs}, 0.86 \mu \mathrm{mol} / \mathrm{h}$ for $(\mathrm{SSmPc})_{\mathrm{n}} / \mathrm{CDs}$, owing to the fact that the excess CDs suppressed the formation of the $(\mathrm{SMPc})_{\mathrm{n}} / \mathrm{CDs}$ carbon nanostructures. The maximum $\mathrm{H}_{2}$ evolution was obtained when the injected CDs was $4 \mathrm{~mL}$. These results indicate the CDs and $(\mathrm{SMPc})_{\mathrm{n}}$ both play vital roles in overall water splitting. Significantly, the best overall water splitting was achieved under the conditions of using $1.13 \mathrm{~g}$ urea and $4 \mathrm{~mL}$ CDs simultaneously. It turned out that the $\mathrm{N}, \mathrm{S}$, and metal concentrations exhibit a synergistic effect on the photocatalytic activity of the $(\mathrm{SMPc})_{\mathrm{n}} / \mathrm{CDs}$ system. 
Table 1. Electrochemical data and photocatalytic activities of (SMPc $)_{n} / C D s$ photocatalysts.

\begin{tabular}{|c|c|c|c|c|c|}
\hline \multirow[t]{2}{*}{ Photocatalysts } & \multirow[t]{2}{*}{$E_{\text {номо }}(\mathrm{eV})$} & \multirow[t]{2}{*}{$E_{\text {LUMO }}(\mathrm{eV})$} & \multirow[t]{2}{*}{$\mathrm{n}$} & \multicolumn{2}{|c|}{ Rate $(\mu \mathrm{mol} / \mathrm{h})$} \\
\hline & & & & $\mathrm{H}_{2}$ & $\mathrm{O}_{2}$ \\
\hline$(\mathrm{SCrPc})_{\mathrm{n}} / \mathrm{CDs}$ & -6.45 & -4.04 & 1.88 & 0.46 & 0.21 \\
\hline$(\mathrm{SCdPc})_{\mathrm{n}} / \mathrm{CDs}$ & -6.30 & -4.06 & 1.84 & 0.40 & 0.19 \\
\hline$(\mathrm{SFePc})_{\mathrm{n}} / \mathrm{CDs}$ & -6.41 & -4.12 & 1.68 & 0.24 & 0.11 \\
\hline$(\mathrm{SZnPc})_{\mathrm{n}} / \mathrm{CDs}$ & -6.38 & -4.07 & 1.79 & $<0.1$ & trace \\
\hline$(\mathrm{SSmPc})_{\mathrm{n}} / \mathrm{CDs}$ & -5.88 & -3.89 & 3.43 & 1.04 & 0.53 \\
\hline$(\mathrm{SCePc})_{\mathrm{n}} / \mathrm{CDs}$ & -6.19 & -3.81 & 3.28 & 0.66 & 0.32 \\
\hline$(\mathrm{SEuPc})_{\mathrm{n}} / \mathrm{CDs}$ & -6.21 & -4.09 & 3.38 & 0.28 & 0.13 \\
\hline$(\mathrm{SPrPc})_{\mathrm{n}} / \mathrm{CDs}$ & -6.60 & -3.96 & 3.26 & $<0.1$ & trace \\
\hline$(\mathrm{SErPc})_{\mathrm{n}} / \mathrm{CDs}$ & -6.43 & -3.87 & 3.19 & $<0.1$ & trace \\
\hline
\end{tabular}

For the sake of understanding photocatalytic water splitting over (SMPc) $)_{n} / \mathrm{CDs}$ via two-electron or four-electron pathway, the following experiments were carried out. Figure $6 \mathrm{a}$ and $\mathrm{b}$ show RRDE collection experiments for $(\mathrm{SCrPc})_{n} / \mathrm{CDs}$ and $(\mathrm{SSmPc})_{n} / \mathrm{CDs}$, respectively. The electron transfer number (n) could be calculated by the following equation: ${ }^{3}$

$$
\mathrm{n}=4 \mathrm{I}_{\text {disk }} /\left(\mathrm{I}_{\text {disk }}+\mathrm{I}_{\text {ring }} / \mathrm{N}\right)
$$

where $\mathrm{I}_{\text {disk }}$ is the disk current density, $\mathrm{I}_{\text {ring }}$ is the ring current density and $\mathrm{N}$ is the RRDE collection efficiency. $\mathrm{N}$ refers to the fraction of the $\mathrm{H}_{2} \mathrm{O}_{2}$ formed at the disk that was collected at the ring ${ }^{64}$ and it was experimentally determined to be 0.24 . The $n$ was calculated to be 1.88 for $(\mathrm{SCrPc})_{\mathrm{n}} / \mathrm{CDs}$, and 3.43 for $(\mathrm{SSmPc})_{\mathrm{n}} / \mathrm{CDs}$. The $\mathrm{n}$ for $(\mathrm{SMPc})_{\mathrm{n}} / \mathrm{CDs}$ is shown in Table 1 . We can conclude that $(\mathrm{SMPc})_{\mathrm{n}} / \mathrm{CDs}(\mathrm{M}=\mathrm{Cr}, \mathrm{Cd}, \mathrm{Fe}, \mathrm{Zn})$ photocatalysts split water into $\mathrm{H}_{2}$ and $\mathrm{O}_{2}$ through a two-electron pathway $\left(\mathrm{H}_{2} \mathrm{O} \rightarrow \mathrm{H}_{2}+\mathrm{H}_{2} \mathrm{O}_{2} ; \mathrm{H}_{2} \mathrm{O}_{2} \rightarrow \mathrm{H}_{2} \mathrm{O}+\mathrm{O}_{2}\right.$ ). While the (SMPc) $/ \mathrm{CDs}(\mathrm{M}$ $=\mathrm{Re}=\mathrm{Sm}, \mathrm{Ce}, \mathrm{Eu}, \mathrm{Pr}, \mathrm{Er}$ ) for overall photocatalytic water splitting is a four-electron pathway 
$\left(\mathrm{H}_{2} \mathrm{O} \rightarrow \mathrm{O}_{2}+\mathrm{H}_{2}\right)$. The reasons for this phenomenon are possibly position of the $\mathrm{VB}$ in the photocatalysts, rich oxygen vacancy (or oxygen vacancy clustering) and high oxygen storagerelease capacity in $(\mathrm{SMPc})_{\mathrm{n}} / \mathrm{CDs}(\mathrm{M}=\mathrm{Re}=\mathrm{Sm}, \mathrm{Ce}, \mathrm{Eu}, \mathrm{Pr}, \mathrm{Er})$ that favorable to the formation of $\mathrm{O}_{2}$ on the catalyst surface. ${ }^{60,65,66}$

The i-t curves of as-prepared (SMPc) $)_{n} / C D s$ under dark and light, respectively, (Figure $6 c$ and d) were carried out to further study the photocatalytic activity in the process of water splitting. It turned out that the photocatalytic activity of $(\mathrm{SMPc})_{\mathrm{n}} / \mathrm{CDs}$ maintained at a high level and there was no apparent catalyst deactivation phenomenon. The curves of $(\mathrm{SMPc})_{\mathrm{n}} / \mathrm{CDs}$ show periodical current oscillation that may result from the generation, adsorption, desorption, and diffusion of $\mathrm{H}_{2}, \mathrm{O}_{2}$ and $\mathrm{H}_{2} \mathrm{O}_{2}$ in the water. ${ }^{3}$
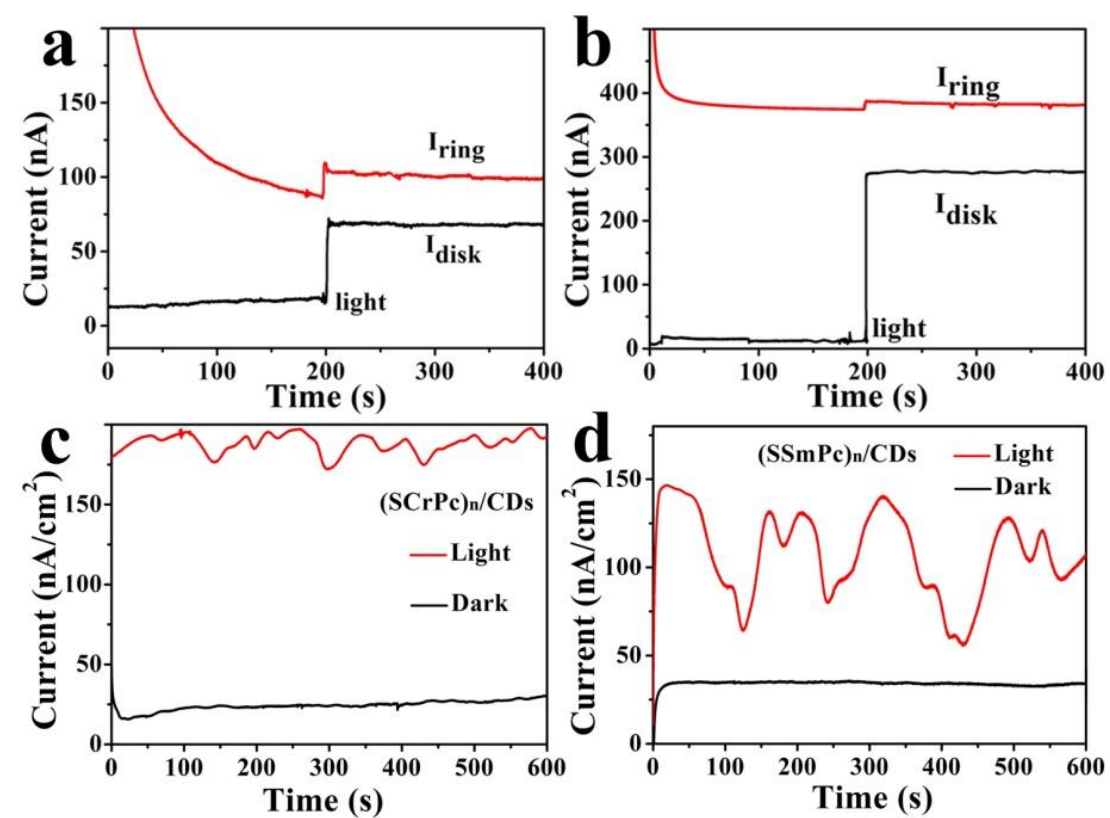
Figure 6. The RRDE collection experiments for $(\mathrm{SCrPc})_{n} / \mathrm{CDs}(\mathrm{a})$ and $(\mathrm{SSmPc})_{\mathrm{n}} / \mathrm{CDs}(\mathrm{b})$. The it curve of $(\mathrm{SCrPc})_{\mathrm{n}} / \mathrm{CDs}(\mathrm{c})$ and $(\mathrm{SSmPc})_{\mathrm{n}} / \mathrm{CDs}(\mathrm{d})$ as photocatalysts.

Figure 7a and $b$ show the UV-vis absorption spectra of free $\mathrm{H}_{2} \mathrm{O}_{2}$ in the reaction solution using $(\mathrm{SCrPc})_{\mathrm{n}} / \mathrm{CDs}$ and $(\mathrm{SSmPc})_{\mathrm{n}} / \mathrm{CDs}$, which demonstrated that $\mathrm{H}_{2} \mathrm{O}_{2}$ was formed in the process of photocatalytic reaction over $(\mathrm{SCrPc})_{n} / \mathrm{CDs}$, and no $\mathrm{H}_{2} \mathrm{O}_{2}$ was detected in the reaction solution after $24 \mathrm{~h}$ irradiation with $(\mathrm{SSmPc})_{\mathrm{n}} / \mathrm{CDs}$ as catalysts (compared with Figure $\left.\mathrm{S} 1\right)$. These results are in agreement with measured band position (Figure $4 \mathrm{~b}$ and $\mathrm{d}$ ). The linear sweep voltammograms (LSV) curves for $(\mathrm{SMPc})_{n} / \mathrm{CDs}$ in different concentrations of $\mathrm{H}_{2} \mathrm{O}_{2}$ solution (Figure S10) exhibit that the (SMPc) $)_{\mathrm{n}} / \mathrm{CDs}$ catalysts have certain capability of decomposition of $\mathrm{H}_{2} \mathrm{O}_{2}$. Figure 7c and d shows $\mathrm{O}_{2}$ evolution originates from $\mathrm{H}_{2} \mathrm{O}_{2}(5 \mathrm{mM}, 100 \mathrm{~mL})$ decomposition versus time curve using $(\mathrm{SMPc})_{\mathrm{n}} / \mathrm{CDs}$ as catalysts under dark. As shown in Figure $7 \mathrm{c}$, the $\mathrm{O}_{2}$ evolution rate over $(\mathrm{SCrPc})_{n} / \mathrm{CDs}$ catalyst was about $24.2 \mu \mathrm{mol} / \mathrm{h}$. Figure $7 \mathrm{~d}$ shows $\mathrm{O}_{2}$ evolution from $\mathrm{H}_{2} \mathrm{O}_{2}(5 \mathrm{mM})$ decomposition versus time curve using $(\mathrm{SSmPc})_{\mathrm{n}} / \mathrm{CDs}$ catalysts, which demonstrated that the $\mathrm{O}_{2}$ evolution rate over $(\mathrm{SCrPc})_{\mathrm{n}} / \mathrm{CDs}$ photocatalyst was about $9.6 \mu \mathrm{mol} / \mathrm{h}$ $(<24.2 \mu \mathrm{mol} / \mathrm{h})$. According to the acquired results, when using $(\mathrm{SCrPc})_{\mathrm{n}} / \mathrm{CDs}$ for photocatalytic water splitting, the $\mathrm{H}_{2} \mathrm{O}_{2}$ in the reaction solution could be detected by UV-vis absorption spectra (Figure $7 \mathrm{a}$ and $\mathrm{b}$, black trace). It can be inferred that the ( $\mathrm{SCrPc})_{\mathrm{n}} / \mathrm{CDs}$ photocatalysts can split water into $\mathrm{H}_{2}$ and $\mathrm{H}_{2} \mathrm{O}_{2}$, and then the $\mathrm{H}_{2} \mathrm{O}_{2}$ can further decompose into $\mathrm{O}_{2}$ and $\mathrm{H}_{2} \mathrm{O}$ with the aid of the $(\mathrm{SCrPc})_{\mathrm{n}} / \mathrm{CDs}$ catalysts. Moreover, the second step $\left(\mathrm{H}_{2} \mathrm{O}_{2} \rightarrow \mathrm{H}_{2} \mathrm{O}+\mathrm{O}_{2}\right)$ is a rate-controlled 
step, which claims the catalysts possess a strong catalytic ability for $\mathrm{H}_{2} \mathrm{O}_{2}$ decomposition (Figure 7c). Consequently, the $(\mathrm{SCrPc})_{n} / \mathrm{CDs}$ as a photocatalyst splits water into $\mathrm{H}_{2}$ and $\mathrm{O}_{2}$ through a two-electron two-step pathway $\left(\mathrm{H}_{2} \mathrm{O} \rightarrow \mathrm{H}_{2}+\mathrm{H}_{2} \mathrm{O}_{2} ; \mathrm{H}_{2} \mathrm{O}_{2} \rightarrow \mathrm{H}_{2} \mathrm{O}+\mathrm{O}_{2}\right)$. For $(\mathrm{SSmPc})_{\mathrm{n}} / C D s$, we assume that it also can split water into $\mathrm{H}_{2}$ and $\mathrm{H}_{2} \mathrm{O}_{2}$ via a two-electron pathway. However, the $\mathrm{H}_{2} \mathrm{O}_{2}$ in the reaction solution cannot be detected based on UV-vis spectral data (Figure $7 \mathrm{a}$ and $b$, blue trace), which indicate either the generated $\mathrm{H}_{2} \mathrm{O}_{2}$ subsequently decomposed completely by the $(\mathrm{SSmPc})_{\mathrm{n}} / \mathrm{CDs}$ catalysts or no $\mathrm{H}_{2} \mathrm{O}_{2}$ was produced. Taking into account results of band positions measured in Figure 4 and the number of electron transferred drawn from Figure 6, one can believe the latter is plausible. In other words, the $(\mathrm{SSmPc})_{n} / \mathrm{CDs}$ as photocatalysts should split water into $\mathrm{H}_{2}$ and $\mathrm{O}_{2}$ through a four-electron pathway $\left(\mathrm{H}_{2} \mathrm{O} \rightarrow \mathrm{H}_{2}+\mathrm{O}_{2}\right)$.
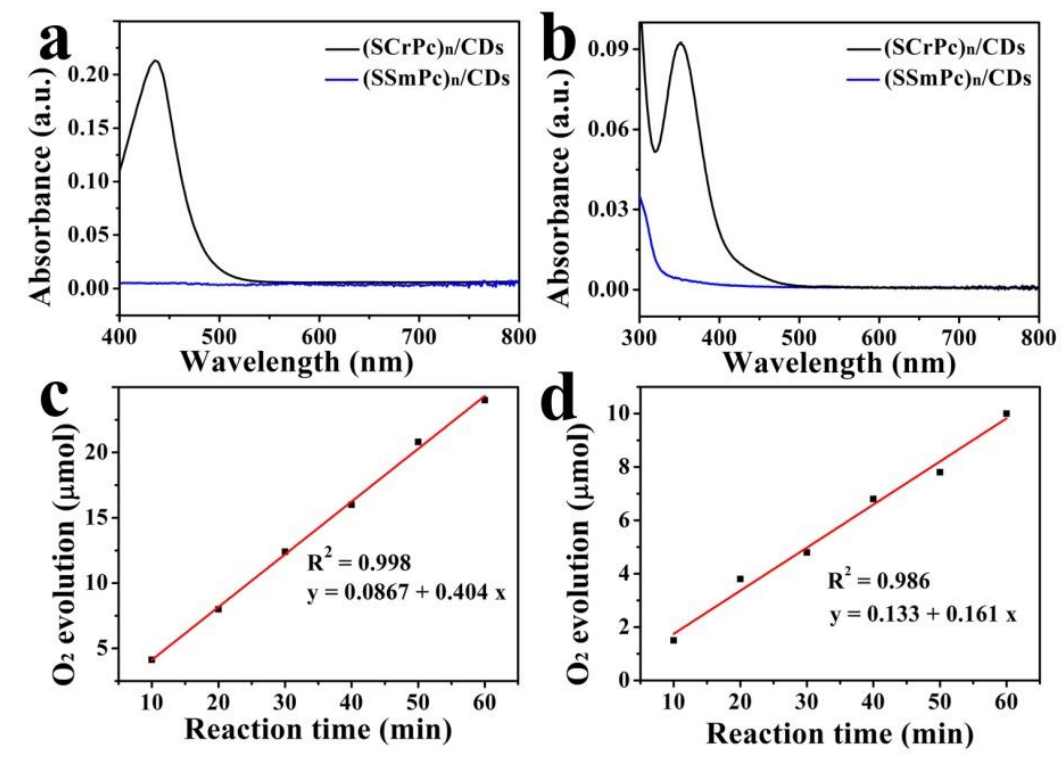

Figure 7. (a) UV-vis absorption spectra of free $\mathrm{H}_{2} \mathrm{O}_{2}$ in the reaction solution containing $1 \% o$ tolidine over $(\mathrm{SCrPc})_{\mathrm{n}} / \mathrm{CDs}$ (black trace) and $(\mathrm{SSmPc})_{\mathrm{n}} / \mathrm{CDs}$ (blue trace) as photocatalysts. (b) 
UV-vis absorption spectra of a reaction solution containing KI (excess) over $(\mathrm{SCrPc})_{\mathrm{n}} / \mathrm{CDs}$ (black trace) and $(\mathrm{SSmPc})_{n} / \mathrm{CDs}$ (blue trace) as photocatalysts. The $\mathrm{O}_{2}$ evolution from $\mathrm{H}_{2} \mathrm{O}_{2}(5$ $\mathrm{mM})$ decomposition versus time curve using $(\mathrm{SCrPc})_{\mathrm{n}} / \mathrm{CDs}(\mathrm{c})$ and $(\mathrm{SSmPc})_{\mathrm{n}} / \mathrm{CDs}(\mathrm{d})$ as catalysts under dark.

To further verify the roles of $\mathrm{CDs}$ in $(\mathrm{SMPc})_{\mathrm{n}} / \mathrm{CDs}$, the photo-induced electron transfer property of CDs was investigated. Figure S11 shows luminescence decays (485 nm excitation, monitored with $550 \mathrm{~nm}$ narrow band pass filter) of the CDs with (Figure S11a) 2, 4dinitrotoluene and (Figure S11b) DEA, as well as corresponding Stern-Volmer plots (Figure S11c and d) for the quenching of luminescence quantum yields, in which Stern-Volmer quenching constants from linear regression was 30.4 and $25.4 \mathrm{M}^{-1}$, respectively. These data indicate that CDs possess electron donating and accepting capabilities. In the current catalyst system, $\mathrm{CDs}$ could act as electron acceptor. In the following experiments, $\mathrm{AgNO}_{3}$ and $\mathrm{Pb}\left(\mathrm{NO}_{3}\right)_{2}$ as indicators were employed respectively to clarify the reduction and oxidation reaction sites in the $(\mathrm{SCrPc})_{\mathrm{n}} / \mathrm{CDs}$ (Figure $8 \mathrm{a}$ and $\left.\mathrm{b}\right)$ and $(\mathrm{SSmPc})_{\mathrm{n}} / \mathrm{CDs}$ (Figure $8 \mathrm{c}$ and d) photocatalysts. As shown in Figure 8a and c, Ag particles were deposited on the surfaces of CDs in the carbon nanostructure, clear lattice spacings of 0.32 and $0.23 \mathrm{~nm}$ are in well agreement with the (002) crystallographic planes of graphitic carbon and (111) lattice planes of $\mathrm{Ag},{ }^{67}$ respectively. It turned out that CDs should be active sites for $\mathrm{H}_{2}$ evolution in the process of water splitting. The HRTEM image in Figure $8 \mathrm{~b}$ shows interplanner spacing of $0.35 \mathrm{~nm}$, which corresponds to the 
(110) planes of $\mathrm{PbO}_{2} .{ }^{68}$ And clear lattice spacing of $0.28 \mathrm{~nm}$ in Figure $8 \mathrm{~d}$ corresponds to the (111) planes of $\mathrm{PbO}_{2} \cdot{ }^{69}$ It suggests the distribution of oxidation reaction sites on catalyst surface (away from CDs).

By combining all the analysis results, the main mechanisms were proposed towards the overall water splitting with $(\mathrm{SMPc})_{\mathrm{n}} / \mathrm{CDs}$ as a photocatalyst, as shown in Figure $\mathrm{S} 12$. When $(\mathrm{SMPc})_{\mathrm{n}} / \mathrm{CDs}$ was illuminated by light with its energy greater than the $E_{\mathrm{g}}$ of the photocatalyst, the photoexcited electrons and holes over the photocatalyst were quickly formed. After that, the transfer of the electrons to the surface of CDs and holes to the surface of $(\mathrm{SMPc})_{\mathrm{n}} / \mathrm{CDs}$ carbon nanostructure rapidly occurs. Simultaneously, the photogenerated electrons reduce $\mathrm{H}^{+}$, which is adsorbed on CDs surfaces, into $\mathrm{H}_{2}$, and the holes are responsible for the oxidation from $\mathrm{H}_{2} \mathrm{O}$ to $\mathrm{H}_{2} \mathrm{O}_{2}$ or $\mathrm{O}_{2 .}{ }^{9,70}$ Then $\mathrm{H}_{2} \mathrm{O}_{2}$ was decomposed into $\mathrm{O}_{2}$ and $\mathrm{H}_{2} \mathrm{O}$ quickly. Additional studies devoted to increasing the rate of $\mathrm{H}_{2}$ and $\mathrm{O}_{2}$ production and the corresponding mechanisms are underway in our laboratory. 

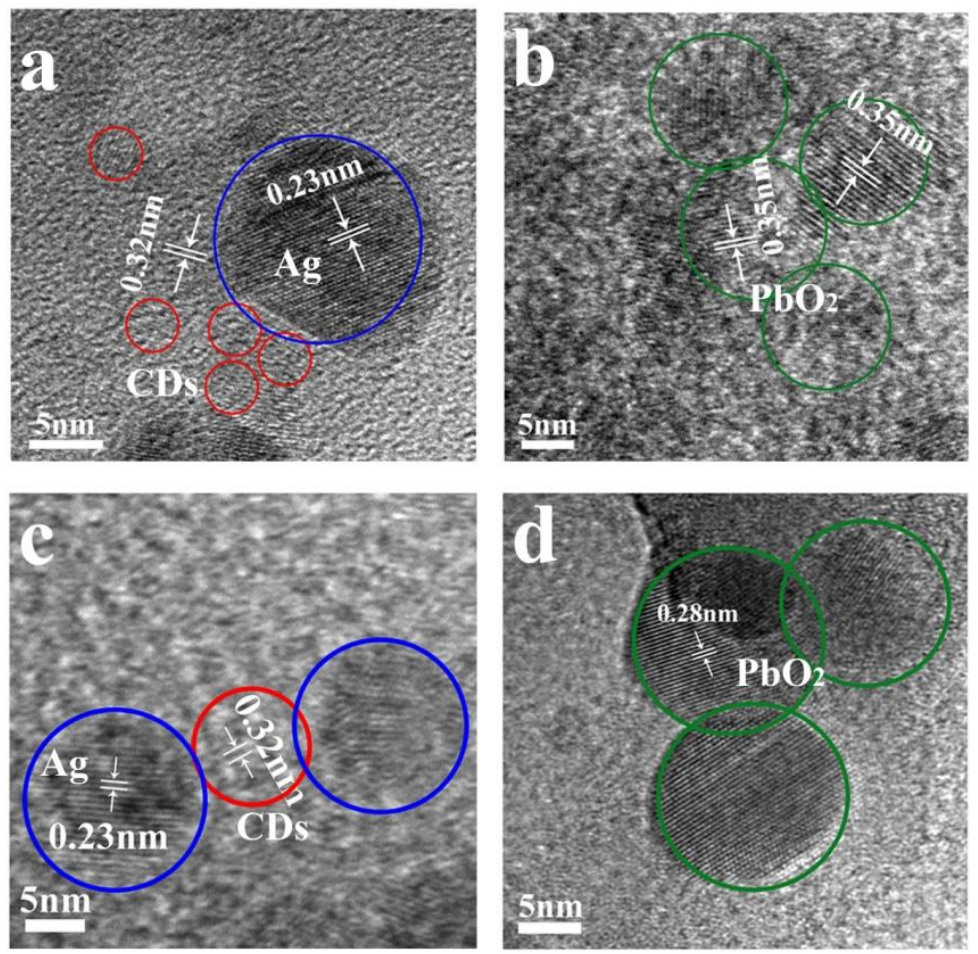

Figure 8. The HRTEM images of reduction sites (a) and oxidation sites (b) over ( $\mathrm{SCrPc})_{\mathrm{n}} / \mathrm{CDs}$. The HRTEM images of reduction sites (c) and oxidation sites (d) over $(\mathrm{SSmPc})_{\mathrm{n}} / \mathrm{CDs}$. The red, blue and green circles represent $\mathrm{CDs}, \mathrm{Ag}$ and $\mathrm{PbO}_{2}$ particles, respectively.

\section{CONCLUSIONS}

We present that a nitrogen, sulfur, transition metal-codoped carbon based nanostructure $\left[(\mathrm{SMPc})_{\mathrm{n}} / \mathrm{CDs}, \mathrm{M}=\mathrm{Cr}, \mathrm{Cd}, \mathrm{Fe}, \mathrm{Zn}, \mathrm{Sm}, \mathrm{Ce}, \mathrm{Eu}, \mathrm{Pr}, \mathrm{Er}\right]$ by a facile pyrolysis method exhibits efficient photocatalytic ability and photostability for overall water splitting without sacrificial agents. Among them, the $\mathrm{CDs}$ in $(\mathrm{SMPc})_{\mathrm{n}} / \mathrm{CDs}$ nanostructure play important roles for photocatalytic water splitting, which not only improve charge seperation but more importantly provide active reduction reaction sites. Furthermore, overall photocatalytic water splitting has 
been achieved on both photocatalysts but they have different reaction pathway. The $(\mathrm{SMPc})_{\mathrm{n}} / \mathrm{CDs}(\mathrm{M}=\mathrm{Cr}, \mathrm{Cd}, \mathrm{Fe}, \mathrm{Zn})$ splits water into $\mathrm{H}_{2}$ and $\mathrm{O}_{2}$ through a two-electron pathway, while $(\mathrm{SMPc})_{\mathrm{n}} / \mathrm{CDs}(\mathrm{M}=\mathrm{Re}=\mathrm{Sm}, \mathrm{Ce}, \mathrm{Eu}, \mathrm{Pr}, \mathrm{Er})$ photocatalyst is via a four-electron pathway. The current photocatalytic efficiency is not satisfactory, but can be improved by optimising the interface between a photocatalyst and CDs which is underway. In total, this discovery provides a regulatory method for the process of complete photocatalytic water splitting and a new possibility for the development of non-noble-metal photocatalytic systems for overall water splitting.

\section{ASSOCIATED CONTENT}

Supporting Information. This material is available free of charge via the Internet at http://pubs.acs.org.

\section{AUTHOR INFORMATION}

\section{Corresponding Author}

* E-mail: $\quad \underline{\text { zhkang@suda.edu.cn }} \quad$ (Z.H. Kang); yangl@suda.edu.cn $\quad$ (Y. Liu); hhuang0618@ suda.edu.cn (H. Huang); junwang.tang@ucl.ac.uk (J.W. Tang).

\section{Notes}

The authors declare no competing financial interest.

\section{ACKNOWLEDGEMENTS}


This work is supported by the Collaborative Innovation Center of Suzhou Nano Science and Technology, the National Natural Science Foundation of China (51422207, 51132006, 51572179, 21471106, 21501126), the Specialized Research Fund for the Doctoral Program of

Higher Education (20123201110018), the Natural Science Foundation of Jiangsu Province of China (BK20140310), China Postdoctoral Science Foundation (2014M560445, 2015T80581), and a project funded by the Priority Academic Program Development of Jiangsu Higher Education Institutions (PAPD).

\section{REFERENCES}

1. Xiang, Q.; Yu, J.; Jaroniec, M. Chem. Soc. Rev. 2012, 41, 782-796.

2. Wang, W.; Tade, M; Shao, Z. Chem. Soc. Rev. 2014, 44, 5371-5408.

3. Liu, J.; Liu, Y.; Liu, N.; Han, Y.; Zhang, X.; Huang, H.; Lifshitz, Y.; Lee, S.; Zhong, J.; Kang, Z. Science 2015, 347, 6225, 970-974.

4. Bai, S.; Jiang, J.; Zhang, Q.; Xiong, Y. Chem. Soc. Rev. 2015, 44, 2893-2939.

6. Chowdhury, P.; Malekshoar G.; Ray, M.; Zhu, J.; Ray. A. Ind. Eng. Chem. Res. 2013, 52, 5023-5029.

7. Fabian, D.; Hu, S.; Singh, N.; Houle, F.; Hisatomi, T.; Domen, K.; Osterloh, F.; Ardo S. Energy Environ. Sci. 2015, 8, 2825-2850.

8. Shen, S.; Shi, J.; Guo, P.; Guo, L. Int. J. Nanotechnol. 2011, 8, 523-591.

9. Hisatomi, T.; Kubota, J.; Domen, K. Chem. Soc. Rev. 2014, 43, 7520-7535. 
10. Chen, X.; Shen, S.; Guo, L.; Mao, S. Chem. Rev. 2010, 110, 6503-6570.

11. Esswein, A. J.; Nocera, D. G. Chem. Rev. 2007, 107, 4022-4047.

12. Mateo, D.; Esteve-Adell, I.; Albero, J.; Royo, J. F. S.; Primo, A.; Garcia, H. Nature communications 2016, 7, 11819-11819.

13. Choi, C.; Kwon, H.; Yook, S.; Shin, H.; Kim, H.; Choi, M. J. Phys. Chem. C. 2014, 118, 30063-30070.

14. Kudo, A.; Miseki, Y. Chem. Soc. Rev. 2009, 38, 253-278.

15. Li, H.; Kang, Z.; Liu, Y.; Lee, S. J. Mater. Chem. 2012, 22, 24230-24253.

16. Tang, L.; Ji, R.; Cao, X.; Lin, J.; Jiang, H.; Li, X.; Teng, K.; Luk, C.; Zeng, S.; Hao, J.; Lau, S. ACS Nano, 2012, 6, 5102-5110.

17. Li, H.; He, X.; Kang, Z.; Huang, H.; Liu, Y.; Liu, J.; Lian, S.; Tsang, C.; Yang, X. ; Lee, S. Angew. Chem. Int. Ed. 2010, 49, 4430-4434.

18. Zhou, L.; Liu, J.; Zhang, X.; Liu, R.; Huang, H.; Liu, Y.; Kang, Z. Nanoscale 2014, 6, 5831-5837.

19. Han, Y.; Huang, H.; Zhang, H.; Liu, Y.; Han, X.; Liu, R.; Li, H.; Kang. Z. ACS Catal. 2014, 4, 781-787.

20. Zhang, H.; Huang, H.; Ming, H.; Li, H.; Zhang, L.; Liu, Y.; Kang, Z. J. Mater. Chem. 2012, 22, 10501-10506.

21. Li, H.; Liu, R.; Liu, Y.; Huang, H.; Yu, H.; Ming, H.; Lian, S.; Lee, S.; Kang, Z. J. Mater. Chem. 2012, 22, 17470-17475. 
22. Tang, D.; Liu, J.; Wu, X.; Liu, R.; Han, X.; Han, Y.; Huang, H.; Liu, Y.; Kang, Z. ACS Appl. Mater. Inter. 2014, 6, 7918-7925.

23. Yang, Y.; Liu, J.; Han, Y.; Huang, H.; Liu, N.; Liu, Y.; Kang, Z. Phys. Chem. Chem. Phys. 2014, 16, 25350- 25357.

24. Yu, B.; Kwak, S. J. Mater. Chem. 2012, 22, 8345-8353.

25. Yu, H.; Zhao, Y.; Zhou, C.; Shang, L.; Peng, Y.; Cao, Y.; Wu, L.; Tung, C.; Zhang, T. J. Mater. Chem.A 2014, 2, 3344-3351.

26. Yu, H.; Shi, R.; Zhao, Y.; Waterhouse, G.; Wu, L.; Tung, C.; Zhang, T. Adv. Mater. 2016, 28, 9454-9477.

27. Gholipour, M.; Dinh, C.; Béland, F.; Do, T. Nanoscale 2015, 7, 8187-8208.

28. Hou, J.; Cheng, H.; Takeda, O.; Zhu, H. Energy Environ. Sci. 2015, 8, 1348-1357.

29. Lim, S. Y.; Shen, W.; Gao, Z. Q. Chem. Soc. Rev. 2015, 44, 362-381.

30. Zhao, Y. F.; Jia, X. D.; Waterhouse, G. I. N.; Wu, L. Z.; Tung, C. H.; O'Hare, D.; Zhang, T. R. Adv. Energy Mater. 2015, 1501974.

31. Zhang, J. T.; Zhao, Z. H.; Xia, Z.H.; Dai, L. M. Nature nanotechnology 2015, 10, 444452.

32. Zheng, Y.; Jiao, Y.; Ge, L.; Jaroniec, M.; Qiao, S. Z. Angew. Chem. 2013, 125, 31923198.

33. Dua, Y.; Guo, S. J. Nanoscale 2016, 8, 2532- 2543. 
34. Duan, J. J.; Chen, S.; Chambers, B. A.; Andersson, G. G.; Qiao, S. Z. Adv. Mater. 2015, $27,4234-4241$

35. Xu, Q.; Liu, Y.; Gao, C.; Wei, J. F.; Zhou, H. J.; Yusheng Chen, Y. S.; Dong, C. B.; Sreeprasad, T. S.; Li, N.; Xia, Z. H. J. Mater. Chem. C 2015, 3, 9885-9893.

36. Sorokin, A. B. Chem. Rev. 2013, 113, 8152-8191.

37. Bottari, G.; Torre, G. D. L.; Guldi, D. M.; and Tomás, T. Chem. Rev. 2010, 110, 67686816.

38. Ming, H.; Ma, Z.; Liu, Y.; Pan, K. M.; Yu, H.; Wang, F.; Kang, Z. H. Dalton Trans. 2012, 41, 9526-9531.

39. Moser, F. H.; Thomas, A. L. J. Chem. Educ. 1964, 41, 245-249.

40. Drinkard. W. C.; Bailar, Jr, J. C. J. Am. Chem. Soc. 1959, 81, 4795-4797.

41. Gürek, A. G.; Ahsen, V.; Luneau, D.; Pécaut, J. Inorg. Chem. 2001, 40, 4793-4797.

42. Kirin, I. S.; Moskalev, P. N.; Makashev Russ, Y. A. J. Inorg. Chem. 1965, 10, 10651066.

43. Kato, H.; Asakura, K.; Kudo, A. J. Am. Chem. Soc. 2003, 125, 3082-3089.

44. Matsumoto, Y.; Noguchi, M.; Matsunaga, T. J. Phys. Chem. B 1999, 103, 7190- 7194.

45. Abramczyk, H.; Brozek-Pluska, B.; Tondusson, M.; Freysz, E. J. Phys. Chem. C 2013, 117, 4999-5013.

46. Lu, J.; Yang, J. X.; Wang, J. Z.; Lim, A.; Wang, S.; Loh, K. P. ACS Nano. 2009, 3, 23672375 . 
47. Li, X. M.; Zhang, S. L.; Kulinich, S. A.; Liu, Y. L.; Zeng, H. B. Sci. Rep. 2014, 4, 49764983.

48. Wang, D. D.; Huang, J.; Li, X.; Yang, P.; Du, Y. K.; Goh, C. M.; Lu, C. J. Mater. Chem. A 2015, 3, 4195-4202.

49. Dou, X. N.; Lin, Z.; Chen, H.; Zheng, Y.Z.; Lu, C.; Lin, J. M. Chem. Commun. 2013, 49, $5871-5873$.

50. Ho, W. K.; Zhang, Z. Z.; Lin, W.; Huang, S. P.; Zhang, X. W.; Wang, X. X.; Huang, Y. ACS Appl. Mater. Interfaces 2015, 7, 5497-5505.

51. Liu, R. H.; Huang, H.; Li, H. T.; Liu, Y.; Zhong, J.; Li, Y. Y.; Zhang, S.; Kang, Z. H. ACS Catal. 2014, 4, 328-336.

52. Zhang, C. Z.; Hao, R.; Liao, H. B.; Hou, Y. L. Nano Energy. 2013, 2, 88-97.

53. (a) Zhao, Z. W.; Sun, Y. J.; Luo, Q.; Dong, F.; Hui, L.; Ho, W. K. Less is better. Sci. Rep. 2015, 5, 14643-14657; (b) Milošev, I.; Strehblow, H. H.; Navinšek, B. Surface and Coatings Technology 1995, 74-75, 897-902.

54. Kilian, A. S.; Bernardi, F.; Pancotti, A.; Landers, R.; Siervo, A. D.; Morais, J. J. Phys. Chem. C 2014, 118, 20452-20460.

55. Gu, H. B.; Rapole, S. B.; Huang, Y. D.; Cao, D. M.; Luo, Z. P.; Wei, S. Y.; Guo, Z. H. J. Mater. Chem. A 2013, 1, 2011-2021.

56. Zhang, X.; Hsu, A.; Wang, H.; Song, Y.; Kong, J.; Dresselhaus, M. S.; Tomás, P. ACS nano. 2013, 7, 7262-7270. 
57. Du, D. H.; Li, P. C.; Ouyang, J. Y. ACS Appl. Mater. Interfaces 2015, 7, 26952-26958.

58. (a) Lau, V. W.; Mesch, M. B.; Viola Duppel, Volker Blum, Jürgen Senker and Bettina V. Lotsch. J. Am. Chem. Soc. 2015, 137, 1064-1072; (b) Zhang, J.; Wang, Z. J.; Li, L.; Zhao, J. H.; Zheng, J. F.; Cui, H. J.; Zhu, Z. P. J. Mater. Chem. A 2014, 2, 8179-8183.

59. (a) Meng, D. M.; Zhan, W. C.; Guo,Y.; Guo, Y. L.; Wang, L.; Lu, G. Z. ACS Catal. 2015, 5, 5973-5983; (b) Zhang, M. Y.; Shao, C. L.; Guo, Z. C.; Zhang, Jingbo Mu, J. B.; Cao, T. P.; Liu, Y. C. ACS Appl. Mater. Interfaces 2011, 3, 369-377.

60. Guo, M.; Lu, J.Q.; Wu, Y.N.; Wang, Y. J.; Luo, M. F. Langmuir 2011, 27, 3872-3877.

61. Patra, D.; Chiang, C. C.; Chen, W. A.; Wei, K. H.; Wu, M. C.; Chu, C. W. J. Mater. Chem. A 2013, 1, 7767-7774.

62. Xie, G. C.; Zhang, K.; Guo, B. D.; Liu, Q.; Liang, F.; Gong, J. R.Adv. Mater. 2013, 25, 3820-3839.

63. (a) Xie, Y. B.; Yuan, C. W. Appl. Catal. B: Environ. 2003, 46, 251-259; (b) Shi, H. X.; Zhang, T. Y.; An, T. C.; Li, B.; Wang, X. Journal of Colloid and Interface Science 2012 , $380,121-127$.

64. Parimi, N. S.; Umasankar, Y.; Atanassov, P.; Ramasamy, R. P. ACS Catal. 2012, 2, 3844.

65. Liu, X. W.; Zhou, K. B.; Wang, L.; Wang, B.Y.; Li, Y. D. J. Am. Chem. Soc. 2009, 131, 9, 3140-3141. 
66. Smrma, D.D.; Hegde, M. S.; Rao, C. N. R. J. Chem. Soc., Faradsy Trans. 2, 1981, 77, 1509-1502.

67. Liu, H.; Feng, Y.; Chen, D.; Li, C. Y.; Lei, C. P.; Yang, J. J. Mater. Chem. A. 2015, 3, 3182-3223.

68. Cao, M. H.; Hu, C. W.; Peng, G.; Qi, Y.J.; Wang, E. B. J. Am. Chem. Soc. 2003, 125, 4982-4983.

69. Li, Q. J.; Liu, B. B.; Wang, L.; Li, D. M.; Liu, R.; Zou, B.; Cui, T.; Zou, G. T. J. Phys. Chem. Lett. 2010, 1, 309-314.

70. Ran, J. G.; Zhang, J.; Yu, J. G.; Jaroniec, M.; Qiao, S. Z. Chem. Soc. Rev. 2014, 43, 7787-7812. 


\section{Table of Contents graphic}

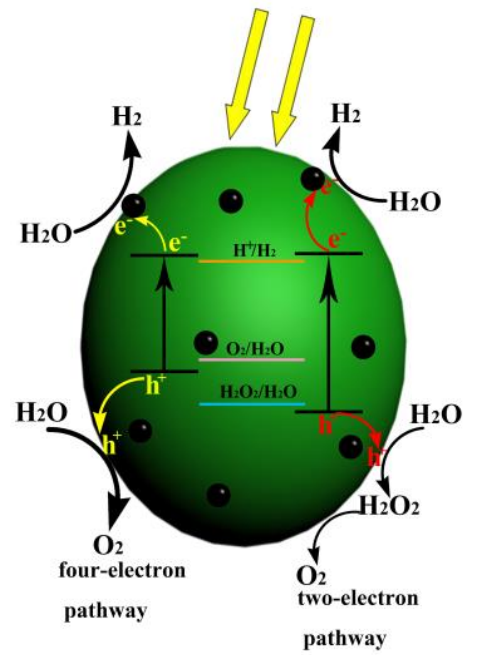

